\title{
Antikoagulation für OP ersatzlos aussetzen
}

\author{
Im Umfeld eines operativen Eingriffs kann die Antikoagulation von Patienten mit Vorhofflimmern \\ mit Heparin überbrückt werden. Doch auch wenn sie ersatzlos unterbrochen wird, nehmen \\ Thromboembolien nicht zu - dafür kommt es deutlich seltener zu schweren Blutungen.
}

In eine randomisierte, doppelblinde Studie wurden 1.884 Patienten mit Vorhofflimmern aufgenommen. Sie wurden seit mindestens drei Monaten mit Warfarin, das in den USA statt Phenprocoumon gebräuchlich ist, antikoaguliert und benötigten einen elektiven operativen Eingriff. Warfarin wurde fünf Tage vor der Operation abgesetzt und 24 Stunden postoperativ wieder verabreicht. Nach Zufallskriterien erhielten die Patienten am 3. und am 2. Tag vor der Operation sowie 5-10 Tage danach zweimal täglich subkutan entweder niedermolekulares Heparin (100 IU/kg KG Dalteparin; $\mathrm{n}=934)$ oder Placebo $(\mathrm{n}=950)$.

Innerhalb von 30 Tagen nach dem Eingriff kam es in der Heparin-Gruppe zu zwei Schlaganfällen und zwei transitorischen ischämischen Attacken $(0,4 \%)$. In der Placebogruppe kam es zu drei Schlaganfällen $(0,3 \%)$. Statistsch ent- spricht dies einer Nicht-Unterlegenheit von Placebo. Mehr noch: Im gleichen Zeitraum traten unter Heparin 29 schwere Blutungen auf $(3,2 \%)$, unter Placebo nur $12(1,3 \%, \mathrm{p}=0,005)$.

- Douketis JD, Spyropoulos AC, Kaatz S et al. Perioperative Bridging Anticoagulation in Patients with Atrial Fibrillation. N Engl J Med. 2015;373:823-33

\section{KOMMENTAR}

Jedes Jahr muss bei etwa einem von sechs Patienten mit Vorhofflimmern ein operativer Eingriff durchgeführt und die Antikoagulation unterbrochen werden. Dieser Zeitraum wird üblicherweise mit einem niedermolekularen Heparin überbrückt, um perioperative Thromboembolien zu minimieren. Dazu gibt es zahlreiche Beobachtungsstudien - doch die fundamentale Frage nach der Notwendigkeit blieb bisher unbeantwortet. Deshalb geben Leitlinien unklare und teils widersprüchliche Empfehlungen.
Jetzt zeigt sich, dass Thromboembolien im Placeboarm nicht häufiger sind als bei Überbrückung mit einem Heparin. Außerdem sind schwere Blutungen ohne Heparin signifikant seltener. Leider war der mittlerere CHADSScore der Patienten mit 2,3 relativ niedrig; es traten daher nur wenige thromboembolische Ereignisse auf. Immerhin aber handelt es sich um die erste randomisierte, doppelblinde Studie an einer respektablen Patientenzahl. Übrigens zeigt eine Subgruppenanalyse der RE-LY-Studie mit einem neuen oralen Antikoagulans das gleiche Ergebnis. Die neuen Daten sprechen also dafür, bei kurzfristigen Unterbrechungen der antithrombotischen Therapie auf Überbrückungsmaßnahmen mit Heparin zu verzichten. Eine gute Nachricht für praktizierende Ärzte, die häufig diese prästationäre Maßnahme einleiten, die Patienten informieren und mit ihnen die Spritztechnik einüben müssen.

Prof. Dr. med. H. Holzgreve

\section{Ein ungewöhnliches Plattenepithelkarzinom}

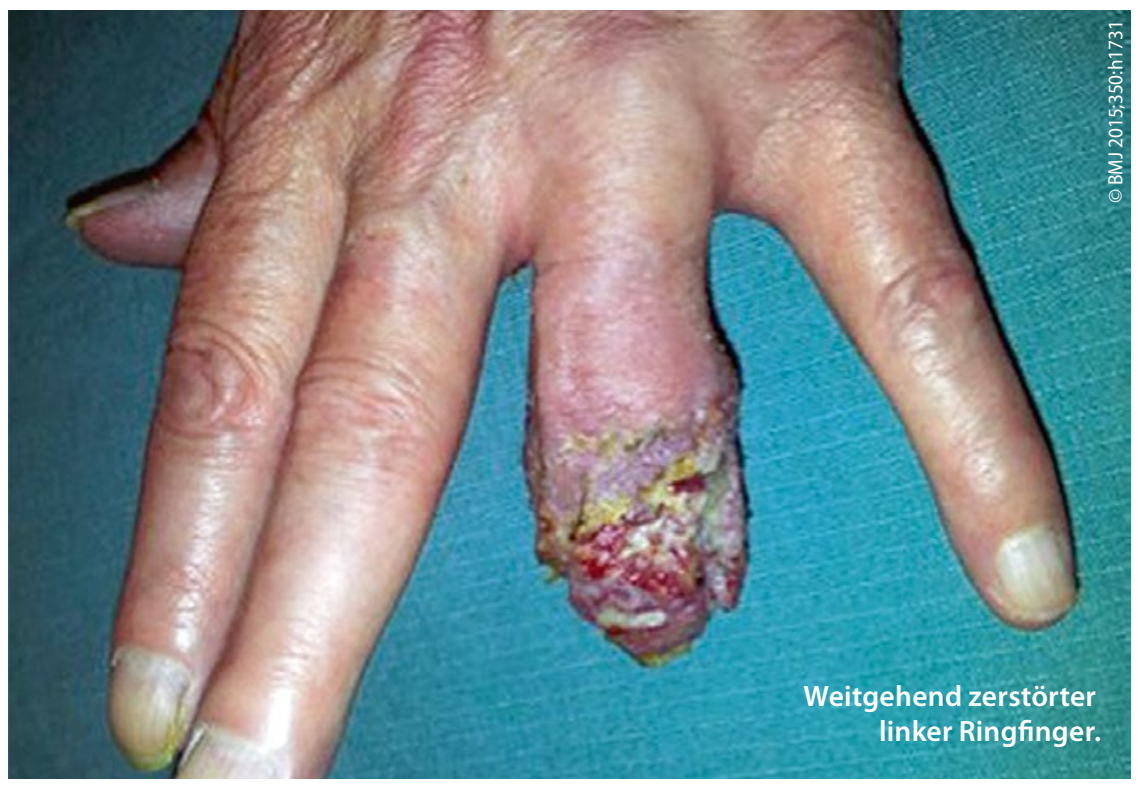

Bei einem 67-jährigen Mann bestanden seit zwei Jahren Schmerzen, eine Schwellung und Exsudation am linken Ringfinger. Die Untersuchung zeigte eine weitgehende Amputation des End- und Mittelgliedes mit zahlreichen Wundhöhlen, aus denen sich faulig riechende Flüssigkeit entleerte. Radiologisch war die Mittelphalanx stark verdünnt. Der Finger wurde am Metacarpophalangealgelenk exartikuliert. Zur Überraschung der behandelnden Ärzte ergab die histologische Untersuchung nicht, wie vermutet, eine Infektion, sondern ein Plattenepithelkarzinom der Haut. Über den kognitiven Zustand des Patienten wird nichts mitgeteilt, doch darf man vermuten, dass dieser beeinträchtigt war.

Prof. Dr. med. H. S. FüeßI

- Abdeh L, Islam A, Swaminathan R

(louai.abdeh@doctors.org.uk).An unusual presentation of squamous cell carcinoma. BMJ 2015;350:h1731 